SHORT COMMUNICATION

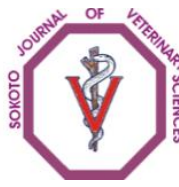

Sokoto Journal of Veterinary Sciences

(P-ISSN 1595-093X/ E-ISSN 2315-6201)

Oluwasile et al/Sokoto Journal of Veterinary Sciences (2014) 12(1): 45-50.

http://dx.doi.org/10.4314/sokjvs.v12i1.7

\title{
Antibiotic usage pattern in selected poultry farms in Ogun state
}

\author{
BB Oluwasile, M Agbaje, OE Ojo \& MA Dipeolu
}

College of Veterinary Medicine, Federal University of Agriculture Abeokuta, PMB 2240 Abeokuta, Ogun State

*Correspondence: Tel.: 2347066174671 ; E-mail:oluwasilebb@unaab.edu.ng

\begin{abstract}
A survey was conducted from March 2011 to July 2011 on antibiotic usage pattern in selected poultry farms in Ogun State. Using a well-structured questionnaire, a total of 58 poultry farms were randomly surveyed from the four geo-political zones of Ogun State. All the 58 (100\%) poultry farms used one or more antibiotics. Antibiotics were commonly administered either for therapy (36.2\%), prophylaxis (29.3\%), or both (32.8\%) and to lesser extent for growth promotion (6.9\%). While Neoceryl ${ }^{R}$ (a commercially prepared broad spectrum antibiotics consisting of neomycin, erythromycin, oxytetracycline, streptomycin and colistin), Enrofloxacin and Furazolidone were the commonest antibiotics used in the study area. Fluoroquinolones were the class of antibiotics commonly used. Thirty-three different patterns of antibiotic usage were observed among the poultry farms, $70.7 \%$ multi-drug usage practices (MDUP) was also observed among the poultry farms. In this study, $50 \%$ of poultry farmers have their antibiotics prescribed by veterinary doctors while $91.4 \%$ acquired antibiotics from veterinary stor es. This study has provided information on commonly used antibiotics and reasons for their use in the study location. It is anticipated that the findings of this survey will contribute to the development of strategies for prudent use of antibiotics in poultry farms.
\end{abstract}

Keywords: Antibiotics, Antibiotic usage pattern, Ogun State, Poultry farms, Survey

Received: 03-09-2013

Accepted: 27-12-2013

\section{Introduction}

Antibiotics are used extensively in both humans and in animals, the worldwide increase in the use of antibiotics, as an integral part of the poultry and other livestock production industries to treat and prevent infectious bacterial diseases, and as growth promoters has led to the problem of the development of bacterial antibiotic resistance over the years (Collignon, 2003; Apata, 2009). Rapid and large poultry production turn-out are partly due to improved feeding and health management practices involving usage of antibiotics as therapeutic agents to treat bacterial diseases in intensive farming systems. In both developing and developed countries, the economic and health advantages of using antibiotics have revolutionized intensive poultry and other livestock production. Majority of the antibiotics used in poultry is for treatment of infections and also to counteract the adverse consequences of stress responses (Oyekunle et al., 2003; Apata, 2009).

Antibiotic use in commercial poultry can be divided into two categories: therapeutic antibiotics and growth-promotant antibiotics (Anonymous, 2003). Therapeutic dose of antibiotics are used for treatment of bacterial infections. Antibiotics used in feed for growth promotion and disease prevention purposes are administered at levels that are lower than those given for the treatment of disease, and therefore, these uses are termed sub-therapeutic. These in-feed antibiotics are capable of exerting a selection pressure on bacterial populations and altering various microbial communities (Lu et al., 2006). Uses of antibiotics in either category have the potential to select for bacterial strains that are resistant to the antibiotics used while still having a positive impact on the health of the animal population. 
The antibiotics in the growth-promotant category are, in some cases, the same antibiotics used in the therapeutic category. The growth-promotant antibiotics are administered only in the birds' feed (Jones \& Ricke, 2003). The decision to use growthpromotant antibiotics in commercial poultry is primarily based on economic factors, i.e., whether the improvements in body weight, feed efficiency, and/or growth rates are worth the cost of the antibiotic (Stutz \& Lawton, 1984; Sirdar et al., 2012). The successful use of antibiotics in veterinary medicine notwithstanding their use has become particularly worrisome, especially for the fact of the potential to extend such drug into the human food chain. Also the possibility of reduced efficacy of such drugs which has been observed in some reports to be administered by non- qualified personnel (Boonmar et al., 1998, Thakur \& Bajaj, 2006). In developed countries, stringent control of antibiotic use coupled with effective surveillance of antibiotic resistance patterns in the population have successfully reduced the prevalence of antibiotic resistance to these agents (Collignon, 2003). The situation in the developing countries like Nigeria is however different, where antimicrobial agents are readily available to people in local drug stores without prescription (Kwaga \& Adesiyun, 1984). Such practice has led to misuse of antibiotics with the associated high prevalence of antibiotic resistance among bacteria from animal and food sources (Enabulele et al., 2008). The aim of this study is to document the way in which antibiotics are used in some selected poultry production units in Ogun State, Nigeria.

\section{Materials and methods \\ Study location}

The study was carried out in some selected poultry farms within the four zones in Ogun State. Ogun State consists of 20 Local Government Areas divided into four zones namely Egba, Ijebu, Yewa and Remo. It lies between latitude $6.2^{\circ} \mathrm{N}$ and $7.8^{\circ} \mathrm{N}$ and longitude $3.0^{\circ} \mathrm{E}$ and $5.0^{\circ} \mathrm{E}$ at an elevation of 51,511 metres above sea level, with an area of 16,762 square kilometers and population of 4,054,272 people.

\section{Study design}

A cross-sectional survey was conducted from March to July 2011. The survey was carried out using a well structured questionnaire. A total of 58 poultry farms were randomly surveyed and information on various antibiotics used within the last one year, sources of antibiotics, sources of prescription and reasons for use in the sampled poultry farms were documented. All interviews were undertaken on spot in the farms and information retrieved from the farm supervisors. Multi-drug usage poultry farms were considered to be either poultry farms that have used three or more different type of antibiotics or commercially prepared broad spectrum antibiotics (that contain three or more different antibiotics) within the last one year.

\section{Data analysis}

Data collation and management was done on Microsoft Excel. Responses to questionnaire were presented in simple frequency.

\section{Results}

From the survey, a total of 58 poultry farms were visited, majority of the poultry farms are small scale poultry units, with population size in the range of 500 - 2000 birds. 58 (100\%) of the poultry farms used one or more antibiotics, 21 (36.2\%) of the poultry farms used antibiotics for therapeutic purpose, 17 (29.3\%) prophylactic purpose, 19 (32.8\%) both therapeutically and prophylactically while 4 (6.9\%) uses antibiotics as growth promoters. 29 (50\%) of the poultry farms indicated that antibiotics were prescribed by veterinary doctors, 25 (43.1\%) practices self-medication and 4 (6.9\%) have antibiotics prescribed by Animal health workers. Fifty-three (91.4\%) sourced antibiotics from Veterinary stores and 5 (8.6\%) sourced antibiotics from local vendors (Table 1). The history of antibiotic usage in the poultry farms in the last one year were presented in Table 2. Thirty-three different patterns of antibiotic usage were observed among the poultry farms, $41(70.7 \%)$ of the poultry farms were multidrug users, 7 (12.1\%) of the poultry farms have used two different types of antibiotics and 10 (17.2\%) of the poultry farms have used one type of antibiotics within last one year. Quinolones were the commonest class of antibiotics used in the poultry farms. Neoceryl ${ }^{R}$ (a commercially prepared broad spectrum antibiotics consisting of neomycin, erythromycin, oxytetracycline, streptomycin and colistin, 36.2\%), Enrofloxacin (27.6\%) and Furazolidone (20.7\%) were the commonest antibiotics used in the study area (Table 3 ). 
Table 1: Antibiotic usage pattern in the some selected poultry farms in Ogun State

\begin{tabular}{|c|c|c|c|}
\hline \multicolumn{4}{|c|}{ Total numbers of Farms visited -58} \\
\hline Items & Response & Frequency & Percentage \\
\hline Use of Antibiotics on the farms & Yes & 58 & 100.0 \\
\hline \multirow[t]{3}{*}{ Source of prescription } & Veterinary doctor & 29 & 50.0 \\
\hline & Self-medication & 25 & 43.1 \\
\hline & Animal health workers & 4 & 6.9 \\
\hline \multirow[t]{4}{*}{ Reason for antibiotics usage } & Treatment & 21 & 36.2 \\
\hline & Prophylaxis & 17 & 29.3 \\
\hline & Treatment and Prophylaxis & 19 & 32.8 \\
\hline & Growth promotion & 4 & 6.9 \\
\hline \multirow[t]{2}{*}{ Source of Antibiotics } & Veterinary store & 53 & 91.4 \\
\hline & Local Vendors & 5 & 8.6 \\
\hline
\end{tabular}

Table 2: History of antibiotic usage in the poultry farms in the last one year

\begin{tabular}{|c|c|c|}
\hline Antibiotic Usage pattern & Number of farms & $\mathrm{s} / \mathrm{n}$ \\
\hline Enrofloxacin, Gentamycin, Furazolidone & 2 & 1 \\
\hline Oxytetracycline, Neoceryl ${ }^{R}$ & 2 & 2 \\
\hline Colistin, Flumequine & 1 & 3 \\
\hline Doxycycline, Gentamycin & 1 & 4 \\
\hline Tylosin, Furazolidone, Neoceryl $^{R}$ & 1 & 5 \\
\hline NCO, Streptomycin, Doxycycline & 1 & 6 \\
\hline Ciprofloxacin & 1 & 7 \\
\hline Ciprofloxacin, Penicillin, Neoceryl $^{R}$ & 2 & 8 \\
\hline Tylosin, Oxytetracycline, Enrofloxacin & 1 & 9 \\
\hline Gentamycin, Ciprofloxacin & 1 & 10 \\
\hline Enrofloxacin & 4 & 11 \\
\hline Enrofloxacin, Furazolidone & 1 & 12 \\
\hline Tylosin, Norfloxacin, Flumequine & 1 & 13 \\
\hline Gentamycin, Doxycycline, Enrofloxacin, Norfloxacin & 1 & 14 \\
\hline NCO, Neoceryl ${ }^{R}$ & 2 & 15 \\
\hline Ciprofloxacin, NCO, Enrofloxacin, Furazolidone, Penicillin & 1 & 16 \\
\hline Furazolidone & 3 & 17 \\
\hline Gentamycin, Streptomycin, Enrofloxacin & 1 & 18 \\
\hline Neoceryl $^{R}$, Penicillin & 2 & 19 \\
\hline Furazolidone, Colistin, Enrofloxacin & 2 & 20 \\
\hline Ciprofloxacin, Furazolidone, Genta mycin, Tylosin, Neoceryl $^{R}$ & 1 & 21 \\
\hline Gentamycin, Enrofloxacin, Neoceryl ${ }^{R}$ & 1 & 22 \\
\hline NCO, Enrofloxacin & 1 & 23 \\
\hline Gentamycin, Doxycycline, Neoceryl $^{R}$ & 1 & 24 \\
\hline Neoceryl $^{R}$ & 10 & 25 \\
\hline Neomycin, Oxytetracycline & 2 & 26 \\
\hline Oxytetracycline & 2 & 27 \\
\hline NCO & 1 & 28 \\
\hline Tylosin, Enrofloxacin & 1 & 29 \\
\hline Tylosin, Neoceryl $^{R}$ & 4 & 30 \\
\hline Enrofloxacin, Oxytetracycline, Genta mycin, Penicillin & 1 & 31 \\
\hline Penicillin, Streptomycin, Norfloxacin & 1 & 32 \\
\hline Penicillin, Streptomycin, Tetracycline & 1 & 33 \\
\hline Total & 58 & \\
\hline
\end{tabular}


Table 3: Antibiotics commonly used in the selected poultry farms in Ogun state

\begin{tabular}{lll}
\hline Antibiotics & Frequency & Percentage \\
\hline Enrofloxacin & 16 & 27.6 \\
Gentamycin & 10 & 17.2 \\
Neoceryl $^{\text {R }}$ & 21 & 36.2 \\
Furazolidone & 12 & 20.7 \\
Colistin & 3 & 5.2 \\
Penicillin & 9 & 15.5 \\
Ciprofloxacin & 5 & 8.6 \\
Norfloxacin & 3 & 5.2 \\
Tylosin & 9 & 15.5 \\
NCO & 6 & 10.3 \\
Oxytetracycline & 6 & 10.3 \\
Doxycycline & 5 & 8.6 \\
Streptomycin & 5 & 8.6 \\
Tetracycline & 1 & 1.7 \\
Flumequine & 2 & 3.5 \\
\hline
\end{tabular}

\section{Discussion}

The antibiotic usage pattern observed in this survey revealed that poultry farms relied heavily on antimicrobial medication to control diseases as most farms were multi-drug users and all the farms used one or more antibiotics for therapeutic, prophylactic and to a lesser extent for growth promotion. This finding is consistent with previous reports (Aarestrup, 1999; Van Duijkeren \& Houwers, 2000; Zhao et al., 2006; Alo \& Ojo, 2007). In the present study, only small percentage of all poultry farms investigated used antibiotics for growth promotion. This is at variance with the findings of Olatoye (2011) who reported that $86 \%$ of poultry farms in Ibadan, Nigeria used antibiotics for growth promotion. This may be due to the facts that many of the farms investigated were small scale farms and may not be financially buoyant to afford continuous addition of antibiotics in bird's feed as growth promoting agents. The higher usage of antibiotics for therapeutic and/or prophylactic purposes as observed in this present study is similar to the findings of Sirdar et al. (2012). Poor environmental sanitation, un-hygienic practices, lack of biosecurity and other management inadequacies leading to increased exposure to bacterial pathogens with resultant immuno-suppression may have contributed to the observed dependence of poultry farms on antibiotics for therapeutic and/or prophylactic purposes.

The various antibiotics used by poultry farms in this survey have also been reported by other authors. Alo \& Ojo (2007) reported a high usage of quinolones, gentamycin, neomycin, tetracycline, streptomycin and tylosin among poultry farms in Ekiti State, Nigeria. Similarly Ogunleye et al. (2008) reported the use of enrofloxacin, tetracycline, gentamycin streptomycin, furatadone, Tylosin norfloxacin among poultry farms in Abeokuta, Nigeria, while Sirdar et al. (2012) also reported the use of oxytetracycline, colistin, Tylosin and enrofloxacin among poultry farms in Khartoun, Sudan. These findings are in agreement with observation in Ogun State as revealed by the present study.

The use of fluoroquinolones which are the commonest class of antibiotics used in the poultry farms is of great concerns. These antibiotics are comparatively new, expensive and are the drug of choice in the treatment of invasive enteric infections both in animals and humans. Their use may be due to their comparative higher advantage of oral preparation and potency. They also serve as a wayout for farmers that are being faced with frustrating experience with refractory bacterial infections caused by the resistant bacteria to the conventional older generation frontline antibiotics. The use of fluoroquinolones is also known to be highly successful and strategic in the treatment of salmonellosis, including infections caused by multiresistant Salmonella serotypes (Reina et al., 1993).

Furazolidone was one of the commonly used antibiotic in the present study, despite the ban on the use of furazolidone as antimicrobials in poultry production due to its possibility of forming residue in 
food and carcinogenic effect on human (Commission Regulation, 1995), most poultry farms still employs the use, as many claimed it to be effective against certain diseases especially salmonellosis, this is of serious public health concerns.

The sourcing of antibiotics by the poultry farms as observed in this study indicates that poultry farmers are well informed. Greater percentage of them source antibiotics from veterinary stores which are possibly owned by qualified and trained professionals such as veterinarians. This finding is at variance with that of Okoli et al. (2002) and Okoli et al. (2005) who reported that non-qualified personnel such as hawkers, small traders and illiterate market women are known to be involved in the retailing of veterinary drugs especially poultry medicines in south eastern, Nigeria. Antibiotic prescription pattern observed in this study revealed that about half of the poultry farms practices self-medication, this has also been reported by Kwaga and Adesiyu, (1984) that antimicrobial agents are rea dily available to people without prescription. Okoli et al. (2002) and Okoli et al. (2005) also reported that selfmedication is rampant among poultry farmers largely due to claim of good experience by farmers, unavailability of veterinary services and the extra cost of veterinary services.

The possible effects of widespread use of antimicrobials in livestock production have been reported (Van den Bogaard \& Stobberingh, 2000; Molla et al., 2003; Oyekunle et al., 2003; Alo \& Ojo, 2007). As observed in this study, the widespread use of antibiotics can lead to the transfer of such drugs into the human food chain in form of drug residues

\section{References}

Aarestrup FM (1999). Association between the consumption of antimicrobial agents in animal husbandry and the occurrence of resistant bacteria among food animals. International Journal of Antimicrobial Agents, 12(4): 279-85.

Alo OS \& Ojo O (2007). Use of antibiotics in food animals; A case of a major veterinary outlet in Ekiti State, Nigeria. Nigerian Veterinary Journal, 28(1): 80-82.

Anonymous (2003). Compendium of veterinary products. North American Compendiums, Inc., Port Huron, MI. Pp 302-303.

Apata DF (2009). Antibiotic Resistance in Poultry. International Journal of Poultry Science, $\mathbf{8}$ (4): 404-408. in animal source foods. This can occur when withdrawal periods are not observed before selling animal products to the general public for human consumption. This can lead to lower efficacy of such drugs when used in for treatment of human illness. Besides, antimicrobial usage can also select for antibiotic resistant bacterial strains with the possibility of transfer of resistant genes to other pathogenic and non-pathogenic bacteria. Human can thus acquire antimicrobial resistant bacteria following consumption of poultry products.

It was concluded that with the widespread and indiscriminate use of antibiotics by the poultry farmers in the study area, abuse is inevitable and public health is at risk. The use of antibiotics by unqualified farmers was due to ineffective implementation of veterinary laws that regulates its use in poultry productions. It is therefore recommended that improvement in the existing veterinary legislations, legal classification and control of use of veterinary drugs with the ultimate aim of protecting the public health will forestall the misuse of antibiotics. Also education of the public on the dangers of indiscriminate use of antibiotics and medications especially in poultry and lives tock farms is imperative, also farmers should be educated on alternative methods of infectious disease management, such as vaccination, environmental sanitation and disease containment, which would decrease the use of antibiotics.

\section{Acknowledgments}

We appreciate all the poultry managers interviewed for their cooperation and time.

Boonmar S, Bangtrakulnonth A, Pornruangwong S, Samosornsuk S, Kaneko K \& Ogawa M (1998). Significant Increase in antibiotic resistance of Salmonella isolates from human beings and chicken meat in Thailand. Veterinary Microbiology, 62(1): 73-80.

Collignon $P$ (2003). A review - the use of antibiotics in food production animals - does this cause problem in human health. Manipulating pig production IX. Proceedings of the ninth biennial conference of the Australasian Pig Science Association (Inc.) (APSA), Femantle, Western Australia, 23-26 November: 73-80.

Commission Regulation (1995). Commission Regulation (EC) 1442/95 of 26 June 1995 
amending Annexes I, II, III and IV of Regulation (ECC) No 2377/90 laying down a Community Procedure for the establishment of maximum residuelimits of veterinary medicinal products in foodstuffs of animal origin. Official Journal of the European Communities, L143, 26-30. http://eur-

lex.europa.eu/smartapi/cgi/sga_doc?smart api !cel exapi !prod!CELEXnumdoc\& $\&$ umdoc $=$ 31995R1442\&model=gui chett\&lg=en retrieved 2011-08-23.

Enabulele OI, Ehwrieme DA \& Aluyi HSA (2008). Resistance pattern of Salmonella Isolates from Food, Animal and Human sources to common antimicrobial agents. Global Journal of Pure and Applied Science, 4(2): 179-182.

Jones FT \& Ricke SC (2003). Observations on the history of the development of antimicrobials and their use in poultry feeds. Poultry Science, 82(4): 613-617.

Kwaga JKP \& Adesiyun AA (1984). Antibiograms of Staphylococcus aureus Isolates from Some Ready -to- Eat Products. Journal of Food Protection, 47(11): 865-867.

Lu J, Hofacre CL \& Lee MD (2006). Emerging technologies in microbial ecology aid in understanding the effect of monensin on necrotic enteritis. Journal of Applied Poultry Research, 15(1):145-153.

Molla B, Alemayehu D \& Salah W (2003). Sources and distribution of Salmonella serotypes isolated from food animals, slaughterhouse personnel and retail meat products in Ethiopia 1997-2002. Ethiopian Journal of Health Development, 17(1): 63-70.

Ogunleye AO, Oyekunle MA \& Sonibare AO (2008). Multi-drug resistant Escherichia coli isolates of poultry origin in Abeokuta, South Western Nigeria. Veterinarski Arhiv,78 (6), 501-509.

Okoli IC, Anyaegbunam CN, Etuk EB, Opara MN \& Udedibie ABI (2005). Entrepreneurial Characteristics and Constraints of Poultry business in Imo State, Nigeria. Journal of Agriculture and Social Research, 5(1): 25-32.

Okoli IC, Nwosu Cl, Okoli GC, Okeudo NJ \& Ibekwe V (2002). Drug management of anti-microbial resistance in avian bacterial pathogen in Nigeria. International Journal of
Environmental Health and Human Development, 3(1): $39-48$.

Olatoye IO (2011). Antibiotics use and resistance patterns of Salmonella species in poultry from Ibadan, Nigeria. Tropical Veterinarian, 29(1): 28-35

Oyekunle MA, Shodiya SA \& Jimoh IK (2003). Reservoir of antimicrobial Resistant Salmonellae among poultry in a Local government area in Ogun State, Nigeria. Asset Journal International Series A, 3(4): 71 $-80$.

Reina J, Gomez J, Serra A \& Borell N (1993). Analysis of the antibiotic resistance detected in 2043 strains of Salmonella enterica subsp. enterica isolated in stool cultures of Spanish patients with acute diarrhoea (1986-1991). Journal of Antimicrobial Chemotherapy, 32(5): 765769.

Sirdar MM, Picard J, Bisschop S \& Gummow B, (2012). A questionnaire survey of poultry layer farmers in Khartoum State, Sudan, to study their antimicrobial awareness and usage patterns', Onderstepoort Journal of Veterinary Research 79(1): 8 pages.

Stutz MW \& Lawton GC (1984). Effects of diet and antimicrobials on growth, feed efficiency, intestinal Clostridium perfringens, and ileal weight of broiler chicks. Poultry Science, 63(10):2036-2042.

Thakur YR \& Bajaj BK (2006). Antibiotic resistance and molecular characterization of poultry isolates of Salmonella by RAPD-PCR. World Journal of Microbiology and Biotechnology, 22(11): 1177-1183.

Van den Bogaard AE \& Stobberingh EE (2000). Epidemiology of resistance to antibiotics. Links between animals and humans. International Journal of Antimicrobial Agents. 14(4): 327-33.

Van Duijkeren E \& Houwers DJ (2000). A critical assessment of antimicrobial treatment in uncomplicated Salmonella enteritis. Veterinary Microbiology, 73(1): 61-75.

Zhao S, McDermott PF \& Friedman S (2006). Antimicrobial resistance and genetic relatedness among Salmonella from retail foods of animal origin: NARMS retail meat surveillance. Food-borne Pathogen and Diseases, 3(1): 106-117. 